\title{
Proliferation in human gastrointestinal epithelium using bromodeoxyuridine in vivo: data for different sites, proximity to a tumour, and polyposis coli
}

\author{
C S Potten, M Kellett, D A Rew, S A Roberts
}

\begin{abstract}
The distribution of DNA synthesising cells in the crypts of the epithelium in human small and large bowel after injection of bromodeoxyuridine into patients has been studied in relation to the position of the cells in the crypt using immunohistochemistry. Different sites of normal epithelium have been studied. The ileum has a shorter crypt and a very significantly smaller total cell population size. However, it has similar peak labelling index (LI) values to the colon, while the rectum has a lower peak $L I$ value. The mean position of the label occurs at the 17th cell position in the ileum and at about the 22 nd position in both the colon and rectum. The overall mean $L I$ is significantly higher in the ileum at $17.8 \%$, intermediate in the colon at $10.3 \%$, and lowest in the rectum at $8.5 \%$. There is thus an inverse relation between the likelihood of developing a tumour and the rate of cell proliferation as measured by the LI. Assuming a value of 8.6 hours for the duration of $S$, the data suggest that the cell cycle time in the mid crypt region is about 30 hours for the ileum and colon and about 37 hours for the rectum. Samples taken adjacent (within $1 \mathrm{~cm}$ ) to a tumour show a general dampening of proliferative activity at all cell positions compared with samples taken more than $\mathbf{5} \mathrm{cm}$ from a tumour. This is illustrated by the average $L I$, which is about $5.4 \%$ in the colon adjacent to a tumour compared with $10 \%$ distant; comparable values for the rectum are $4.6 \%$ and $8.5 \%$. Samples taken from two patients with polyposis coli show distributions with a significant difference in skewness compared with normal colon and a general shifting of the distribution to the right, that is to higher cell positions. There is a significant increase in the mean cell position and the position of the peak $L I$ in the polyposis coli samples.
\end{abstract}

Cancer of the colon is the second most common cancer in western populations. Kurihara and Aoki, ' from a study of mortality statistics, have predicted an increasing trend in colon cancer in Japan, Germany, and the USA up to the year 2000. Patients diagnosed with a primary colonic cancer have an increased risk of subsequently developing additional primary tumours in this tissue, especially in the presence of adenomatous polyps. ${ }^{23}$ There have been reports of abnormal patterns of cell proliferation in the entire colonic mucosa of patients with colonic adenoma or cancer. ${ }^{+6}$ Thus investigations into the process of carcinogenesis in this tissue are indicated.

There is evidence that human mucosal pro- liferation may be modified in benign and malignant disease states. Increased cell proliferative rates are reported in the mucosa of patients with ulcerative colitis. ${ }^{78}$ Familial polyposis coli is a premalignant condition. Atypical proliferation zones are reported in familial polyposis coli polyps and mucosa. ${ }^{910}$ The characteristics of mucosal kinetics may also change with proximity to a tumour. ${ }^{+1112}$ Some authors have reported a change in proliferation with anatomical site along the colon, ${ }^{1314}$ although we have not found this to be the case in a large series of human material. ${ }^{15}$

Studies on the rate of proliferation in human gastrointestinal epithelium may provide some insight into the changes that are involved in adenoma formation and carcinogenesis in this tissue. They may also provide some clues as to the relation between proliferation and the risk of adenocarcinoma development. There have been many studies over the years that have attempted to measure proliferative indices in human intestine. ${ }^{15}$ However, many of these have involved small biopsy samples, short term incubations in vitro using tritiated thymidine, and often relatively few patients. We have recently accumulated many samples of gastrointestinal material from patients undergoing gastrointestinal resection as a consequence of localised gastrointestinal tumours. The patients received bromodeoxyuridine (BrdUrd) shortly before admission to the theatre and the removal of normal and abnormal gastrointestinal tissue. Hence, we are in a position to analyse the in vivo proliferative index in a variety of situations. We have recently reported our technical approach in some detail ${ }^{15}$ and illustrated the sensitivity and power of the technique in detecting differences in proliferation in the normal human colon and rectum.

The presence of BrdUrd incorporated into the DNA of S phase (DNA synthesising) cells is detected here using an appropriate monoclonal antibody and immunohistochemical approaches. We have developed a computer facilitated scoring system, whereby data for each cell position along the sides of the crypts (the crypt column) are recorded sequentially into an appropriately programmed BBC microcomputer. This permits an analysis to be made of the entire pattern of cell proliferation throughout the crypts. Frequency distributions are obtained for the fraction of $S$ phase cells at each cell position. Here, we wish to present further data from this group of patients extending, in the first instance, our studies in the colon and rectum to the ileum, then analysing the proliferative activity adjacent to and distant from tumours in the colon and in the rectum (adjacent to the tumour is a distance of less than $1 \mathrm{~cm}$, distant from the tumour is a distance greater than 
$5 \mathrm{~cm}$ ), and finally to present some data from two patients (who provided five independent samples) with polyposis coli.

\section{Methods}

Details of the patients and the techniques that have been used are presented in detail in our preceding paper. ${ }^{15}$ Briefly, the techniques are as follows.

\section{PATIENTS, DRUG ADMINISTRATION, AND TISSUE} SAMPLES

Seventy five patients (45-86 years old) undergoing surgery for intestinal malignant disease and two with polyposis coli contributed to this study. They consented to receive a single intravenous dose of $250 \mathrm{mg}$ of 5 bromo-2-deoxyuridine (BrdUrd) (the Takeda Company, Japan) administered over 30 seconds in $10 \mathrm{ml}$ of saline. This dose was administered 2.4-16 hours before surgery, at which time 140 samples from various sites of the gastrointestinal tract were obtained from conventional surgical resection specimens up to $30 \mathrm{~cm}$ from the site of the primary tumour. No toxicity was associated with this procedure. Hospital ethical committee approval was obtained. Mucosal strips were excised from surgical resection specimens of colon and rectum, which included both the primary

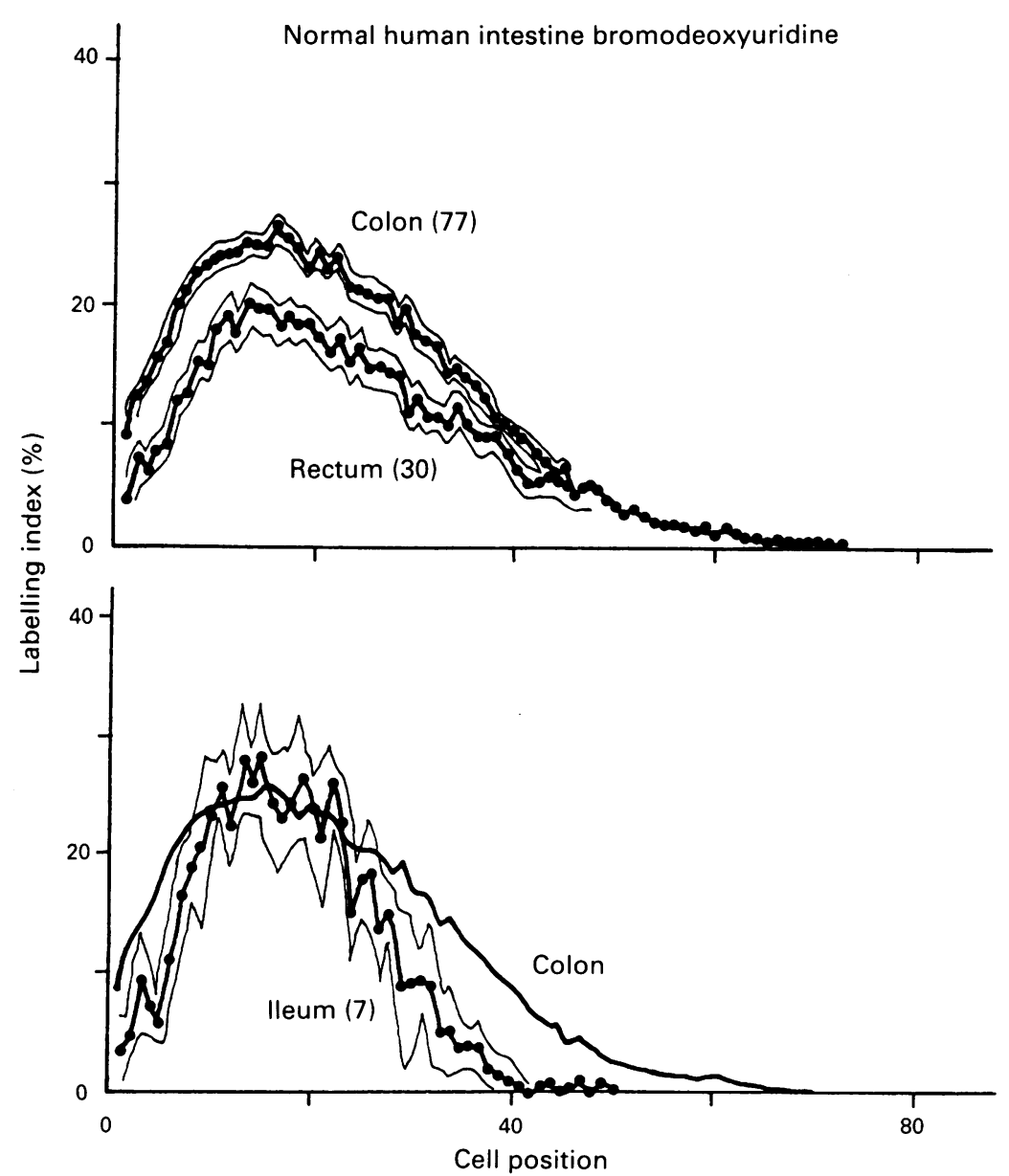

Figure 1: Comparison of the frequency of the labelling index at each cell position in ileal, colonic, and rectal crypts of the human. Each data point is based on at least 50 half crypts scored from each patient in most cases. The number of patients used is given in parenthesis. The standard error limits are shown by the upper and lower pale lines in each case. The mean line for the colonic epithelium is reproduced in the lower panel for comparative purposes. tumour and up to $30 \mathrm{~cm}$ of normal bowel. Two patients undergoing total colectomy for severe polyposis coli were also studied.

In order to test the hypothesis that there may be detectable changes in proliferative activity in mucosa adjacent to primary adenocarcinomas, pairs of mucosal sections were taken $1 \mathrm{~cm}$ and 5 $\mathrm{cm}$ or more from primary tumours (seven colonic, 12 rectal) and stained. Crypt counting was always performed on histologically normal crypts showing no evidence of tumour invasion. The samples were placed in $70 \%$ ethanol within 30 minutes of excision and were stored in a freezer. Sections were cut at $3 \mu \mathrm{m}$ from carefully oriented pieces of tissue.

TISSUE PROCESSING AND IMMUNOHISTOCHEMICAL STAINING

Slides were prepared using every fourth section placed on gelatinised microscope slides. These were dewaxed, air dried, and exposed to $1 \%$ hydrogen peroxide in methanol for 30 minutes to block endogenous peroxidase activity. The tissue was then hydrolysed in 1 normal $\mathrm{HCl}$ at $60^{\circ} \mathrm{C}$ for 8 minutes, neutralised, and washed before being covered with normal rabbit serum diluted 1 in 20. The primary antibody (rat anti-BrdUrd, BU1/75 1 CR1 from Sera Labs, Crawley, Sussex) was then added 1 in 5 for 1 hour at $20^{\circ} \mathrm{C}$. After washing, the secondary antibody (rabbit anti-rat peroxidase, Dako, High Wycombe, Bucks) 1 in 100 was added for 1 hour at $20^{\circ} \mathrm{C}$. After washing, the slides were treated with diaminobenzidine for 15 minutes in the dark, after which the slides were weakly stained with haematoxylin.

\section{SCORING TECHNIQUES}

Good longitudinal sections of crypts were selected for scoring using a $\times 40$ oil objective. The criterion used for selection was that the crypts had to possess a lumen and a crypt base that was at a maximum depth in comparison with all other crypts. The mid point at the crypt base was identified and the crypt was divided into equal longitudinal halves, the lowermost cell nucleus in each half was designated cell position 1 , as a reference point for the computer programme which recorded and analysed the data. The characteristics of each consecutive cell moving up the side of the crypt from cell position 1 was recorded directly into a microcomputer. The information that was recorded was whether the cell was labelled or unlabelled, mitotic or a labelled mitotic cell. The scoring continued up to the mid point on the intercrypt proximal table of cells if a neighbouring crypt was present, or up to the ninth cell position past the neck of the crypt if no neighbouring crypt was present, or to the crypt villus junction if a villus was present. Fifty half crypt sections were scored from each sample wherever possible using a $\times 40$ oil objective. The computer programme which has been developed could then produce frequency histograms for each category of cells and various statistical parameters connected with the data such as the overall mean labelling index $(\mathrm{LI})$, the median, the 95th centile, the peak LI (defined as the 
TABLE I Site variation in human gastrointestinal tract after in vivo bromodeoxyuridine labelling

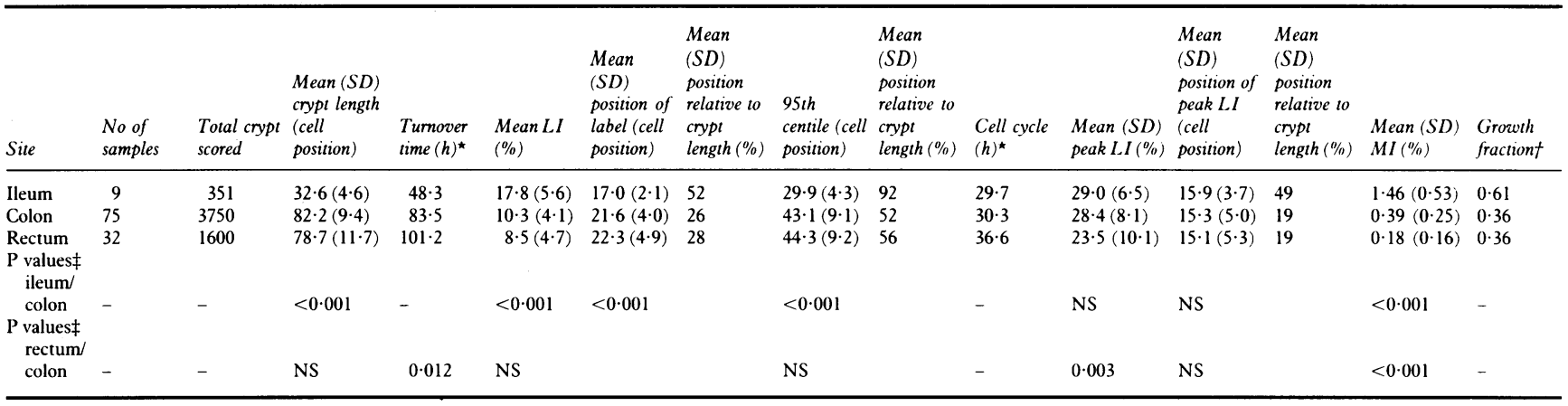

$\star \mathrm{T},+8 \cdot 6 \mathrm{~h}$ (see text).

tGrowth fraction for crypts cell cycle time/turnover time.

$\ddagger$ Mann-Whitney U test.

$\mathrm{LI}=$ labelling index; $\mathrm{MI}=$ mitotic index

Figure 2: The frequency of the labelling index at each cell position in human colonic crypts adjacent to and distant from a tumour. The standard error limits are shown by the faint lines in each case and the number of patients analysed for each curve is shown in parenthesis. Seven patients provided paired samples, both adjacent and distant from tumours.
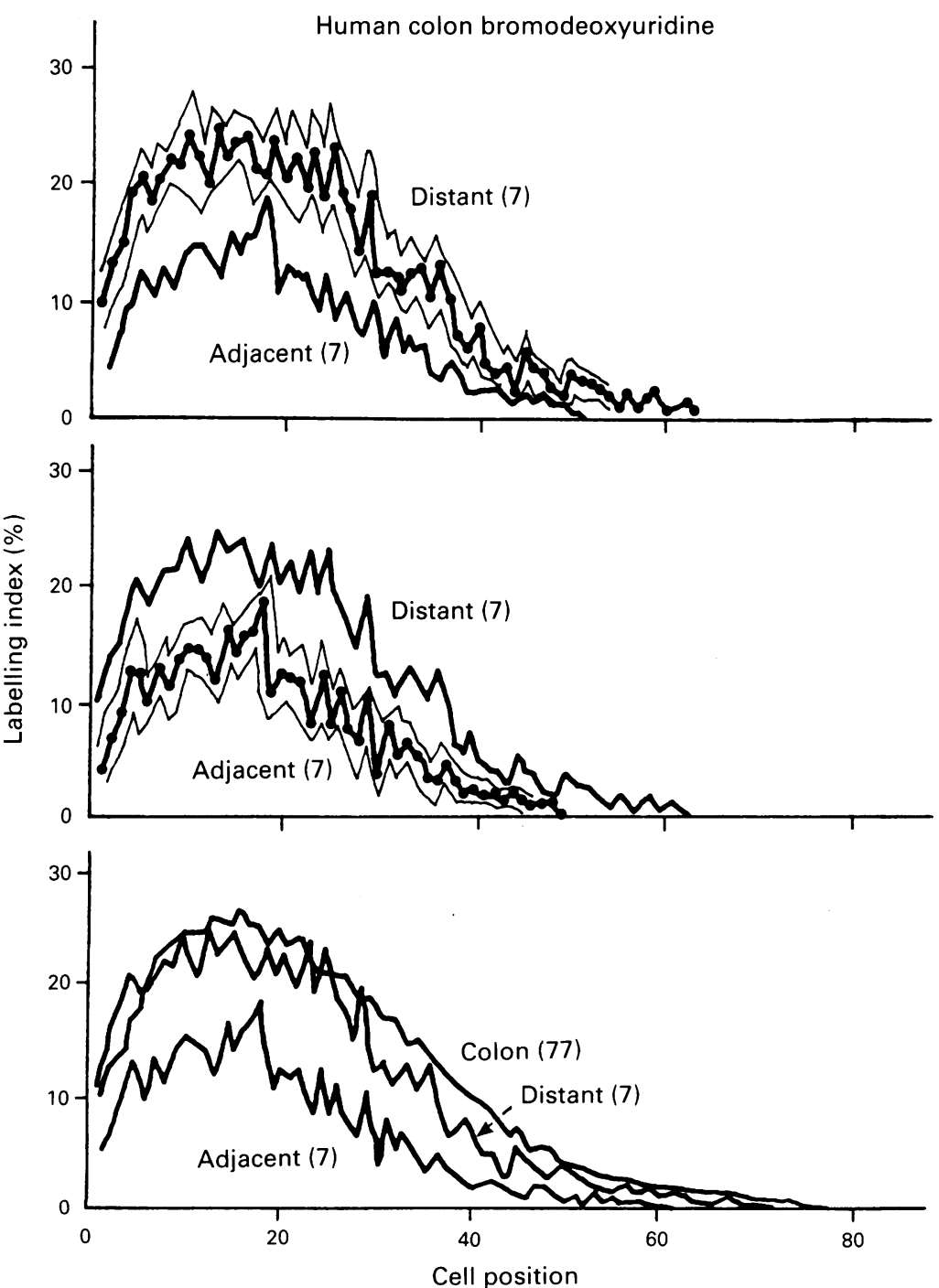

and $\mathrm{P}=$ mean position of the label.

\section{STATISTICAL METHODS} Wilcoxon signed rank test was used to compare

Human colon bromodeoxyuridine paired samples from the same patients adjacent value of the running average five cell positions). Skewness was also determined for some of the data.

$$
\text { Skewness }=\frac{2(\mathrm{LI}) \times(\mathrm{Pi}-\mathrm{P})^{3}}{\mathrm{i}(\mathrm{n}-1)^{3}} \text { where } \mathrm{Pi}=\text { position } \mathrm{i}
$$

Comparisons between the various subgroups of patients (different sites) were performed using the non-parametric Mann-Whitney U test. A

(tour
. The lowest mean (SD) LI is to be found in the rectum at $8.5(4.7) \%$, and the highest LI in the ileum at $17 \cdot 8(5 \cdot 6) \%$, with the colon being intermediate at $10 \cdot 3(4 \cdot 1) \%$. The mean position of the label (a measure of the central tendency of the frequency plots shown in Figure 1$)$ is significantly lower in the ileum $(17 \cdot 0$, $21 \cdot 6$, and $22 \cdot 3$ cell positions respectively for ileum, colon, and rectum). The median values are $16.7,20.0$, and 20.8 respectively. These differences are also reflected when the 95th centile is considered $(29 \cdot 9,43 \cdot 1$, and $44 \cdot 3$ cell positions respectively). This is a measure of how far up the crypt the label spreads. The peak LI is similar in the ileum and colon but is significantly lower in the rectum $(29.0,28.4$, and $23.5 \%$ respectively). However, there is no difference in the position of the peak LI, which occurs at about the 15 th or 16 th cell position in each case. The mean mitotic indices (MI) differ significantly in a fashion similar to the mean LI. In summary, the data on the changes with site show that the ileum has a shorter crypt but has similar peak LI values to the colon, while the rectum has a similar length crypt to the colon but lower peak LI values.

Since the ileal crypts are significantly shorter, an alternative way of analysing the data is to express these parameters relative to the crypt length. If this is done, the mean values occur at $52 \%$ of the crypt length for the ileum and at 26$28 \%$ for the colon and rectum. The 95 th centile occurs at $92 \%$ of the crypt length in the ileum but $52-56 \%$ for the colon and rectum, while the peak LI occurs at $46 \%$ of the crypt length in the ileum and 18 and $19 \%$ for the colon and rectum respectively. There is thus proportionately (in terms of cell position) more proliferation near the crypt base in the colon and rectum.

The ileum has 32.6 cells in the vertical column (longitudinal sections) and $24 \cdot 2(4 \cdot 6)$ cells 

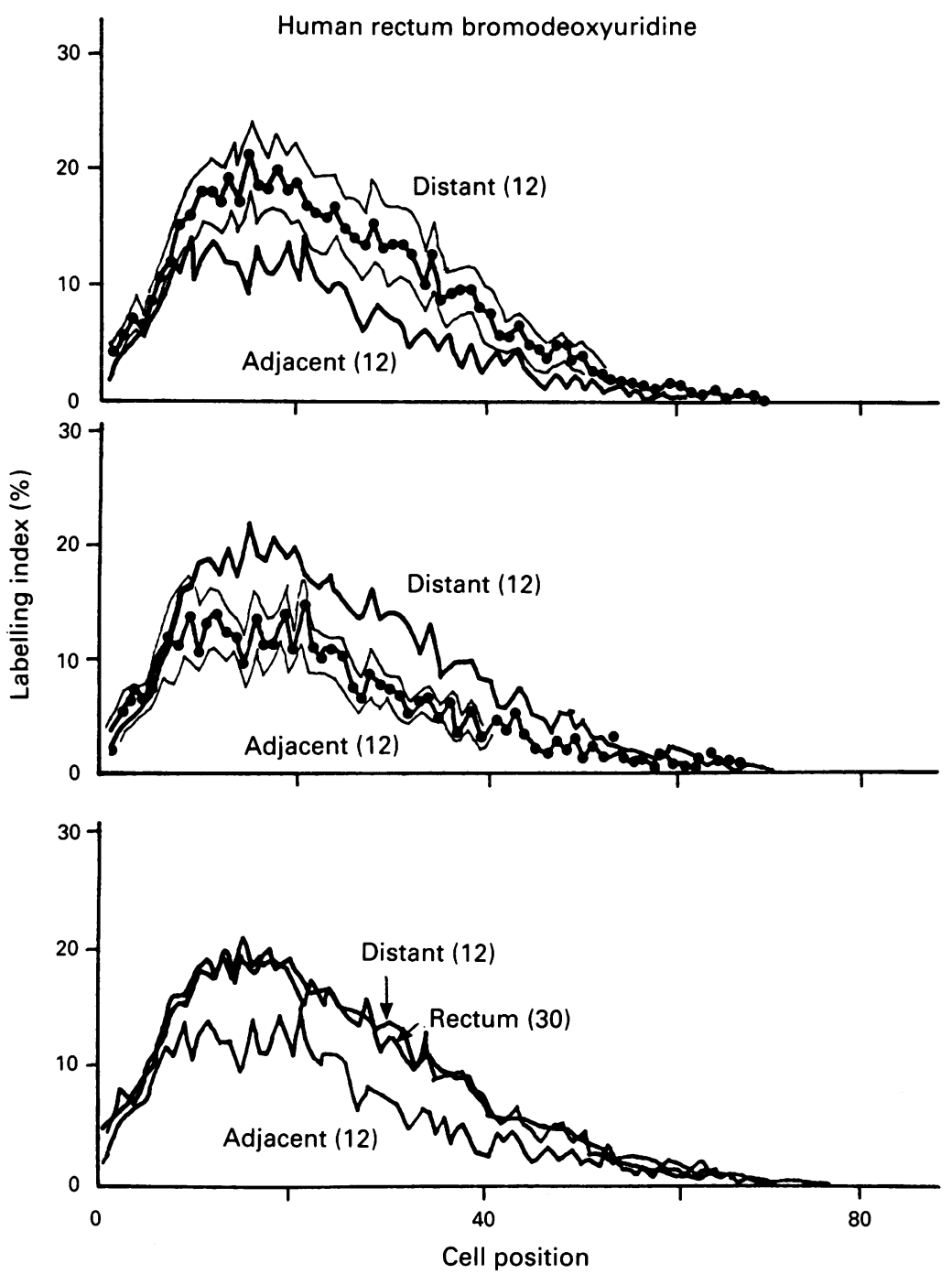

Figure 3: Labelling index frequency plots against cell position in human rectal crypts adjacent to and distant from a tumour. The standard error limits are shown by the upper and lower faint lines in each case and the number of patients analysed is shown in parenthesis. Twelve patients provided paired samples for comparison. in circumference (transverse sections). The product of these multiplied by a geometric correction factor of $0 \cdot 6^{16}$ gives a figure of 473 cells per ileal crypt which can be compared with values of 2044 cells per colonic crypt and 2194 cells per rectal crypt. ${ }^{15}$

The data for changing proliferative indices with proximity of a tumour are presented in Figure 2 for the colon, Figure 3 for the rectum, and in Table II for both sites. For the colon, seven patients provided paired samples adjacent to and distant from the tumour. In the rectum, 12 paired samples were obtained. The general trend for both sites was that the small group of samples distant from the tumour were identical to the previous values shown in Table I for a large group of patients pooled. However, the samples in both cases taken adjacent to the tumour showed a lower LI throughout the entire cell position distribution. This was evident when the mean LI was observed, which was significantly lower either adjacent to the tumour in the colon or adjacent to a tumour in the rectum. The position of the 95th centile was significantly different when the adjacent and distant groups were compared for the colon. There was a significant difference in the value of the peak LI in the adjacent and distant colonic samples. The peak LI for the rectal samples showed a significant difference only when the adjacent to the tumour group was compared with all the pooled distant samples. In summary, the general trend is that samples adjacent to a tumour show a general dampening of the proliferative activity at all cell positions compared with samples taken some distance from a tumour.

The mean LI for both colonic and rectal sites adjacent to tumours in this study was $5 \cdot 0(1 \cdot 8) \%$, which is comparable with a LI of $4.9(0.2) \%$ found in human subjects with no colonic disease. ${ }^{4}$ However, sites distant from tumours have in comparison a raised mean LI of 9.4 $(4 \cdot 4) \%$. This may provide some confirmation of abnormal proliferative activity in the entire large bowel in the presence of colorectal carcinoma.

Two patients provided five samples of polyposis coli. The five samples were taken from different positions in the colon. When all five samples were pooled the data are shown in Figure 4 and Table III. There is a clear and significant shift in the distribution to the right hand side. This is evident from a significant difference in cell position of the 5 th centile, which is higher for the polyposis coli sample (indicating a lower LI and hence proliferation at the crypt base), a significant increase in the mean cell position in the polyposis coli sample, and a significant increase in the cell position of the peak LI in the polyposis coli sample. Overall there is a significant difference in skewness between the normal colon and that of polyposis coli, with polyposis samples showing a more symmetrical distribution.

\section{Discussion}

In vivo labelling of human tumours and tissues

TABLE II Human gastrointestinal tract, adjacent to and distant from a tumour, in vivo bromodeoxyuridine labelling

\begin{tabular}{|c|c|c|c|c|c|c|c|c|c|}
\hline Site & No of samples & $\begin{array}{l}\text { Total crypts } \\
\text { scored }\end{array}$ & $\begin{array}{l}\text { Mean (SD) } \\
\text { crypt length } \\
\text { (cell position) }\end{array}$ & $\underset{(\%)}{\operatorname{Mean}}(S D) L I$ & $\begin{array}{l}\text { Mean (SD) } \\
\text { position of } \\
\text { label (cell } \\
\text { position) }\end{array}$ & $\begin{array}{l}\text { 95th centile } \\
\text { (cell position) }\end{array}$ & $\begin{array}{l}\text { Mean }(S D) \\
\text { peak LI }(\%)\end{array}$ & $\begin{array}{l}\text { Position of } \\
\text { peak LI (cell } \\
\text { position) }\end{array}$ & $\begin{array}{l}\text { Mean }(S D) \\
M I(\%)\end{array}$ \\
\hline $\begin{array}{l}\text { Colon, distant and } \\
\text { pooled }\end{array}$ & 75 & 3750 & $82 \cdot 2(9 \cdot 4)$ & $10 \cdot 3(4 \cdot 1)$ & $21 \cdot 6(4 \cdot 0)$ & $43 \cdot 1(9 \cdot 1)$ & $28 \cdot 4(8 \cdot 1)$ & $15 \cdot 3(5 \cdot 0)$ & $0.39(0.25)$ \\
\hline $\begin{array}{l}\text { Rectum, distant and } \\
\text { pooled } \\
\text { Colon, adjacent } \\
\text { Rectum, adjacent } \\
\text { P values: }\end{array}$ & $\begin{array}{r}32 \\
7 \\
12\end{array}$ & $\begin{array}{r}1600 \\
275 \\
500\end{array}$ & $\begin{array}{l}78 \cdot 7(11 \cdot 7) \\
76 \cdot 4(7 \cdot 4) \\
86 \cdot 7(8 \cdot 2)\end{array}$ & $\begin{array}{l}8 \cdot 5(4 \cdot 7) \\
5 \cdot 4(1 \cdot 7) \\
4 \cdot 6(2 \cdot 0)\end{array}$ & $\begin{array}{l}22 \cdot 3(4 \cdot 9) \\
17 \cdot 9(2 \cdot 7) \\
21 \cdot 3(3 \cdot 8)\end{array}$ & $\begin{array}{l}44 \cdot 3(9 \cdot 2) \\
36 \cdot 2(5 \cdot 7) \\
44 \cdot 7(7 \cdot 9)\end{array}$ & $\begin{array}{l}23 \cdot 5(10 \cdot 1) \\
18 \cdot 1(3 \cdot 6) \\
16 \cdot 4(7 \cdot 1)\end{array}$ & $\begin{array}{l}15 \cdot 1(5 \cdot 3) \\
12 \cdot 9(5 \cdot 1) \\
15 \cdot 4(4 \cdot 6)\end{array}$ & $\begin{array}{l}0 \cdot 18(0 \cdot 16) \\
0 \cdot 17(0 \cdot 16) \\
0 \cdot 14(0 \cdot 14)\end{array}$ \\
\hline $\begin{array}{l}\text { Colon, adj/distant } \\
\text { pairs (W) } \\
\text { All samples }(M-W)\end{array}$ & $\overline{-}$ & - & $\begin{array}{l}\text { NS } \\
\text { NS }\end{array}$ & $\begin{array}{l}<0.018 \\
<0.001\end{array}$ & $\begin{array}{l}\text { NS } \\
0 \cdot 016\end{array}$ & $\begin{array}{l}0 \cdot 043 \\
0 \cdot 023\end{array}$ & $\begin{array}{l}<0.018 \\
<0.001\end{array}$ & $\begin{array}{l}\text { NS } \\
\text { NS }\end{array}$ & $\begin{array}{l}0 \cdot 028 \\
0.010\end{array}$ \\
\hline $\begin{array}{l}\text { Rectum, adj/ } \\
\text { distant pairs (W) } \\
\text { All samples }(M-W)\end{array}$ & - & - & $\begin{array}{l}\text { NS }(0.060) \\
0.025\end{array}$ & $\begin{array}{c}<0.055 \\
0.002\end{array}$ & $\begin{array}{l}\text { NS }(0.055) \\
\text { NS }\end{array}$ & $\begin{array}{l}\text { NS } \\
\text { NS }\end{array}$ & $\begin{array}{l}\text { NS } \\
0.013\end{array}$ & $\begin{array}{l}\text { NS } \\
\text { NS }\end{array}$ & $\begin{array}{l}\text { NS } \\
\text { NS }\end{array}$ \\
\hline
\end{tabular}




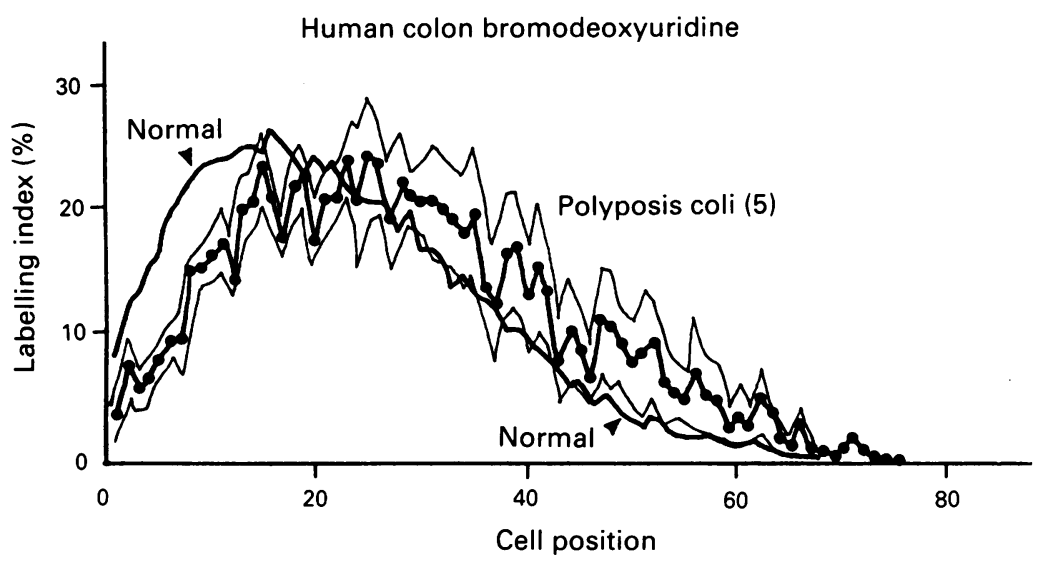

Figure 4: The frequency of the labelling index at each cell position in colonic crypts from two patients who provided five samples of polyposis coli compared with normal human colon.

Standard error limits are shown by the upper and lower faint line in each case.

offers considerable physiological advantages over in vitro techniques. ${ }^{17}$ BrdUrd is a clinically safe alternative to $3 \mathrm{H}$-Thy for in vivo pulse labelling studies when used in the low dose described by the intravenous route. BrdUrd shares a theoretical risk of mutagenicity with all cytotoxic agents and ionising radiations. Although no evidence has emerged of acute or long term toxicity, its clinical research use should usually be confined to consenting adults with malignant or advanced premalignant disease. A unique opportunity arose from a primary study of proliferation in colorectal malignancy to investigate labelled intestinal mucosa from surgical resection specimens.

The results clearly illustrate the sensitivity of the techniques employed here in detecting subtle variations in proliferative activity in different positions of the crypt. This is perhaps well illustrated by the data for the polyposis coli, where the average LI shows no difference from normal colon. However, there is a clear and significant shift in the position of the peak LI and a general movement of proliferation to higher cell positions. Deschner and Lipkin et $a l^{51819}$ have noted similar shifts in the position of labelled cells in patients with a hereditary predisposition to colon cancer. The results illustrate the value of the technique for detecting cell position differences in proliferation and hence probable hierarchy or lineage differences. The technique is currently being extended and applied to analysing differences between sites, pathological conditions, and cell positions for proliferation associated nuclear antigens and oncogene expression.

We acknowledge the possible criticism that virtually all material was derived from patients with colorectal cancer, and that in some way this tissue may differ from the normal human colon. However, detailed histology has not shown any unusual features of this material. This was necessarily a selective retrospective study without appropriate non-malignant clinical controls, which would have been unacceptable. The study was not part of a predetermined protocol. Nevertheless it reports a large and unique series of clinical material.

The results for the three different sites in the intestine are interesting in relation to the distribution of tumours along the gastrointestinal tract. The greatest incidence of tumours is observed in the rectum, which has the lowest average LI, the lowest peak LI, and the lowest mean or average MI and a low LI at the crypt base. The ileum and colon have very similar peak LI values, which occur at the same position in the crypt, and higher (colon) or similar (ileum) LI values at the crypt base compared with the rectum and yet the colon has a significant tumour incidence whereas the ileum rarely develops cancer. However, it should be noted that the position of the peak $\mathrm{LI}$ is proportionately higher up the shorter ileal crypt than it is in the colon ( $49 \%$ of its length compared with $19 \%$ ). Thus it is hard to relate increased cancer risk with rates of proliferation in the crypt generally or rates of proliferation in the stem cell zones near the crypt base. There is proportionately (from a cell position point of view), but not absolutely, more proliferation in the lower regions of the large bowel crypt than in the small bowel crypt.

If the duration of the $S$ phase is known the turnover time for the tissue can be calculated from the duration of $S$ divided by the mean fractional LI and for the mid crypt region where the growth fraction is likely to be close to unity, the cell cycle time can be estimated from the duration of $S$ divided by the peak fractional LI. The duration of $S$ for the colon and rectum was estimated from flow cytometric studies to be about 8.6 hours. ${ }^{15}{ }^{20}$ Using this value the turnover times for the ileum, colon, and rectum respectively were $48 \cdot 3$ hours, 83.5 hours, and $101 \cdot 2$ hours. If we assume that the duration of $S$ lies between 7 and 14 hours, we can state that the turnover times for these sites lie within the ranges 39-79, 68-136, and 82-165 hours respectively. Using the peak LI values and assuming that in this mid region of the crypt the growth fraction is close to unity, the cell cycle times can be calculated to be $29 \cdot 7$ hours, $30 \cdot 3$ hours, and $36 \cdot 6$ hours respectively. This suggests that the mid crypt transit cell cycle times may be similar in the colon and ileum and slightly longer in the rectum. The ratio between this calculated cell cycle time and the turnover time provides some indication for the growth fraction for the entire crypt, which is estimated to be $0.61,0.36$, and

TABLE III Human gastrointestinal tract, polyposis coli in vivo bromodeoxyuridine labelling

\begin{tabular}{|c|c|c|c|c|c|c|c|c|c|c|c|}
\hline Site & $\begin{array}{l}\text { No of } \\
\text { samples }\end{array}$ & $\begin{array}{l}\text { Total crypts } \\
\text { scored }\end{array}$ & $\begin{array}{l}\text { Mean (SD) } \\
\text { crypt length } \\
\text { (cell } \\
\text { position) }\end{array}$ & $\begin{array}{l}\text { Mean }(S D) \\
L I(\%)\end{array}$ & $\begin{array}{l}\text { Mean (SD) } \\
\text { position of } \\
\text { label (cell } \\
\text { position) }\end{array}$ & Skewness & $\begin{array}{l}\text { 95th centile } \\
\text { (cell } \\
\text { position) }\end{array}$ & $\begin{array}{l}\text { 5th centile } \\
\text { (cell } \\
\text { position) }\end{array}$ & $\begin{array}{l}\text { Mean }(S D) \\
\text { peak LI }(\%)\end{array}$ & $\begin{array}{l}\text { Mean }(S D) \\
\text { position of } \\
\text { peak LI } \\
\text { (cell } \\
\text { position) }\end{array}$ & $\begin{array}{l}\text { Mean }(S D) \\
M I(\%)\end{array}$ \\
\hline $\begin{array}{l}\text { Colon } \\
\text { Polyposis coli }\end{array}$ & $\begin{array}{r}75 \\
5\end{array}$ & $\begin{array}{r}3750 \\
250\end{array}$ & $\begin{array}{l}82 \cdot 2(9 \cdot 4) \\
78 \cdot 3(9 \cdot 4)\end{array}$ & $\begin{array}{l}10 \cdot 3(4 \cdot 1) \\
10 \cdot 6(3 \cdot 6)\end{array}$ & $\begin{array}{l}21 \cdot 6(4 \cdot 0) \\
26 \cdot 6(5 \cdot 3)\end{array}$ & $\begin{array}{l}0.57(0.24) \\
0.32(0.11)\end{array}$ & $\begin{array}{l}43 \cdot 1(9 \cdot 1) \\
48 \cdot 8(10 \cdot 6)\end{array}$ & $\begin{array}{l}3 \cdot 8(1 \cdot 4) \\
6 \cdot 4(1 \cdot 3)\end{array}$ & $\begin{array}{l}28 \cdot 4(8 \cdot 1) \\
26 \cdot 0(6 \cdot 5)\end{array}$ & $\begin{array}{l}15 \cdot 3(5 \cdot 0) \\
22 \cdot 4(7 \cdot 2)\end{array}$ & $\begin{array}{l}0.39(0.25) \\
0.26(0.13)\end{array}$ \\
\hline normal` & - & - & NS & NS & 0.045 & 0.006 & NS & 0.002 & NS & 0.027 & NS \\
\hline
\end{tabular}

^Mann-Whitney U test.

$\mathrm{LI}=$ labelling index; $\mathrm{MI}=$ mitotic index . 
0.36 respectively for the ileum, colon, and rectum. The longer the tissue turnover time the greater the duration of exposure of individual cells to possible dietary or lumenal carcinogens.

The data for the effects of tumour proximity were somewhat surprising, since they clearly showed that the normal epithelium immediately adjacent to a tumour has a general suppression of proliferation throughout all the cell positions relative to the distributions that are observed at sites distant from the tumour. This observation is contrary to some presented elsewhere ${ }^{+21}$ and suggests that the tumour is not releasing stimulatory growth factors that have an effect on adjacent tissue but in contrast is suppressing proliferation either by distortion of the tissue, and hence a suppression of supply of nutrients and oxygen, or by the release of toxic or necrotic inducing agents, or finally by releasing inhibitory or growth factor suppressors that diffuse into the adjacent epithelium. Our observations do not preclude a stimulation of stromal/epithelial cells in the colon as a whole. Possibly, epithelial growth outstrips the stromal changes locally which results in a local decrease in nutrients or oxygen or an increase in toxins. We have not analysed these samples for increased cytotoxic effects. Clearly these observations warrant further, more detailed investigations.

While adenomas retain a reasonably ordered crypt like structure, their striking proliferative feature is the random distribution of BrdUrd labelled cells throughout the crypt structure, unlike normal crypts. This renders them more suitable for flow cytometric quantitative analysis of their proliferative indices. We have also measured the LI immunohistochemically in adenoma sections to be $9 \cdot 5(3 \cdot 6) \%$ based on 1000 epithelial cells scored from each of four different patients. This is intermediate between the normal rectal LI $(8 \cdot 5 \%)$ and that of colorectal carcinomas $\left(12 \cdot 1 \%\right.$, see $\left.{ }^{20}\right)$.

None of the evidence presented here can be considered to be conclusive evidence or rebuttal of any hypothesis concerning the genesis of neoplasia from human colorectal mucosa. However, we are able to draw together some important observations.

Firstly, neither the overall rate of cell proliferation in mucosa nor the proportion of proliferating cells, nor the proportion of crypt base (stem) proliferating cells seem to correlate with the likelihood of neoplastic change in the tissue.

Secondly, altered patterns of proliferation seem to indicate a malignant tendency in polyposis coli, and particularly in villous adenomas. Thus, altered controls to the inter-relation of proliferating cells, such as cell recognition mechanisms, may make an important contribution to the malignant phenotype. Indeed, because the rate of tumour growth is a balance between cell production and cell loss, a diminished rate of proliferation is quite possible in tumours compared with mucosa, in which cell loss and production are precisely balanced.

We conclude that the combination of quantitative techniques which we have described offers substantial advantages for the study of colorectal mucosal proliferation, both in animal models and in human diseases, where the clinical circumstances are appropriate. Our data will form the basis for further investigations into the relation between crypt cell turnover and colorectal proliferative diseases.

This work has been supported by the Cancer Research Campaign. We are grateful to Mr R Stradling and Dr R Buchanan from the Department of Pathology, St Mary's Hospital, Portsmouth, and to Mr P C Weaver, Mr M R Thompson, and Professor I Taylor from the Surgical Units at St Mary's and the University of Southampton for their support and help. Finally, we are particularly grateful to for their support and help. Finally, we are particularly grateful to data at the Paterson Institute in Manchester.

1 Kurihara M, Aoki K. Mortality of cancer of the digestive organs: the past, present and future. Gann Monograph on Cancer Research 1986; 31: 3-17.

2 Schottenfield D, Berg JW, Vitsky B. Incidence of multiple primary cancers. II. Index cancers arising in the stomach and lower digestive system. F Natl Cancer Inst 1969; 43: 77-86.

3 Bussey $\mathrm{H}$, Wallace M, Morson BC. Metachronous carcinoma of the large intestine polyps. Proc $R$ Soc Med 1967; 60: 20810 .

4 Terpestra OT, Blankenstein van M, Dees J, Eilers GAM. Abnormal pattern of cell proliferation in the entire colonic mucosa of patients with colon adenoma or cancer. Gastroenterology 1987; 92: 704-8.

5 Lipkin M, Blattner WA, Gardner EJ, Burt RW, Lynch H, Deschner E, et al. Classification and risk assessment of individuals with familial polyposis Gardner's syndrome, and familial non-polyposis colon cancer from [3H] Thymidine labelling patterns in colonic epithelial cells. Cancer Res 1983; 44: 1899-904

6 Romagnoli P, Filipponi F, Bandettini L, Brugnola D. Increase of mitotic activity in the colonic mucosa of patients with colorectal cancer. Dis Colon Rectum 1984; 27: 305-8.

7 Serafini EP, Kirk AP, Chambers TJ. Rate and pattern of epithelial cell proliferation in ulcerative colitis. Gut 1981; 22: 648-52

8 Bleiberg $\mathrm{H}$, Mainguet $\mathrm{P}$, Galand P, Chrétien J, DupontMairesse N. Cell renewal in the human rectum; an in vitro autoradiographic study on active ulcerative colitis. Gastroautoradiographic study on
enterology $1970 ; 58: 851-5$.

9 Bleiberg H, Mainguet P, Galand P. Cell renewal in familial polyposis. Comparison between polyps and adjacent healthy mucosa. Gastroenterologv 1972; 63: 240-5.

10 Lightdale $C$, Lipkin $M$, Deschner $E$. In vivo measurements in familial polyposis: kinetics and location of proliferating cells in colonic adenomas. Cancer Res 1982; 42: 4280-3.

11 Bleiberg H, Galand P. In vitro autoradiographic determination of cell kinetic parameters in adenocarcinomas and adjacent healthy mucosa of human colon and rectum. Cancer Res 1976; 36: 325-8.

12 Deschner EE, Maskens AP. Significance of the labelling index and labelling distribution as kinetic parameters in colorectal mucosa of cancer patients and DMH treated animals. Cancer 1982; 50: 1136-41

13 Sunter JP, Wright NA, Appleton DR. Cell population kinetics in the epithelium of the colon of the male rat. Virchows Arch [B] 1978; 26: 275-87.

14 Sunter JP, Watson AJ, Wright NA, Appleton DR. Cell proliferation at different sites along the length of the rat colon. Virchows Arch [B] 1979; 32: 75-87.

15 Potten CS, Kellett M, Roberts SA, Rew DA, Wilson GD. The measurement of in vivo proliferation in human colorectal mucosa using bromodeoxyuridine. Gut 1992; 33: 71-8.

16 Potten CS, Roberts SA, Chwalinski S, Loeffler M, Paulus U. The reliability in scoring mitotic activity in longitudinal The reliability in scoring mitotic activity in longitudinal
sections of the crypts of the small intestine. Cell Tissue Kinet sections of the crypts of the small intestine. Cell Tissue Kine 1988; $21: 231-16$.

17 Chwalinski S, Potten CS, Evans G. Double labelling with bromodeoxyuridine and ' $\mathrm{H}$-thymidine of proliferative cells in small intestinal epithelium in steady state and after irradiation. Cell Tissue Kinet 1988; 21: 317-29.

8 Deschner E, Lewis CM, Lipkin M. In vitro study of human rectae epithelial cells. A typical zone of $\mathrm{H}^{i}$ Thymidine incorporation in mucosa of multiple polyposis. 7 Clin Invest 1963; 42: 1922-8

19 Deschner GF, Lipkin M. Proliferative in colonic mucosa in familial polvposis. Cancer $1975 ; 35$; +13-9.

20 Rew DA, Wilson GD, Taylor I, Weaver PC. The in vivo proliferation kinetics of human colorectal cancer. Br f Surg

21 Bleiberg H, Salhadin A, Galand P. Cell cycle parameters in human colon. Cancer 1977; 39: 1190-4. 